\title{
Giant lipoma over the back
}

\section{Ketan Vagholkar*, Isha Bhatnagar, Suvarna Vagholkar}

\begin{abstract}
Department of General Surgery, D. Y. Patil University School of Medicine, Navi Mumbai, Maharashtra, India
\end{abstract}
Received: 15 January 2022

Accepted: 02 February 2022

\section{*Correspondence:}

Dr. Ketan Vagholkar,

E-mail:kvagholkar@yahoo.com

Copyright: (C) the author(s), publisher and licensee Medip Academy. This is an open-access article distributed under the terms of the Creative Commons Attribution Non-Commercial License, which permits unrestricted non-commercial use, distribution, and reproduction in any medium, provided the original work is properly cited.

\begin{abstract}
Lipoma is one of the most common soft tissue tumor arising from the mesenchyme. It is slow growing, encapsulated, and usually benign in nature. Tumors over the back, shoulder, and neck region have a high propensity to assume large size thereby getting redefined as a giant lipoma when they exceed $10 \mathrm{~cm}$ in width or weigh more than 1000 grams. MRI is the investigation of choice for evaluating giant lipomas. Fine needle aspiration cytology (FNAC) or frozen section may be pertinent in suspected cases of liposarcoma. Complete surgical incision is the treatment of choice. A case of a giant lipoma on the back of a 64-year-old lady is presented with a view to revisit conceptual understanding of the clinical evaluation, investigation, and management of giant lipomas.
\end{abstract}

Keywords: Giant, Lipoma, Back, Diagnosis, Treatment

\section{INTRODUCTION}

Lipomas are the most common mesenchymal tumors. ${ }^{1}$ They usually occur most frequently in mature adults. The incidence is equal in both sexes, especially in the fifth decade of life. They are usually seen on the back, shoulder, and neck region. ${ }^{1,2}$ In majority of cases, they are slow growing and asymptomatic to start with, but may assume a very large size. Giant lipomas, which by definition exceed $10 \mathrm{~cm}$ in width or weigh more than 1000 grams, can cause cosmetic concerns as well as have higher incidence of malignant transformation. ${ }^{2}$

\section{CASE REPORT}

A 64 your old lady, presented with history of a swelling over the back in the left lower thoracic region since 5 years. The swelling increased in size over the past two years but due to non-availability of surgical facilities imposed by the Covid-19 lockdown, the patient was seriously concerned about the growing size of swelling. It also interfered with clothing. The patient did not have any history of co-morbidities or any history of trauma. On physical examination, there was a large lobulated swelling over the back, in the left lower thoracic region, extending horizontally from the midline to the posterior axillary fold. The swelling was soft in consistency. However, its mobility over the underlying muscle could not be ascertained. The overlying skin was normal (Figure 1). An MRI of the dorso-lumbar region revealed a large sized swelling measuring $14 \times 10 \times 10 \mathrm{~cm}$ with fat intensity within the subcutaneous layer over the lower dorsal lumbar region on the left side. There was indentation of the underlying para-spinal muscles without any deep infiltration. There was no intra-spinal extension (Figure 2 and 3). Patient underwent surgery. While under anesthesia in right lateral position the extent of the tumor was marked followed by marking of the incision (Figure 4) A wide local excision of the lipoma was performed taking utmost care to resect all the lobulations until the underlying muscle was seen (Figure 5). The dimensions of the specimen exceeded $10 \mathrm{~cm}$ and weighed $1150 \mathrm{gm}$. Negative suction tube drain was placed in view of the large dead space created by removal of the tumor. This was removed on the fifth postoperative day. Skin staples were removed on the twelfth postoperative day. Wound healing was complete without any complications. Histopathological examination of the specimen revealed features suggestive of a lipoma. There was no evidence of any liposarcoma. Patient has been following up for the past six months without any recurrence. 


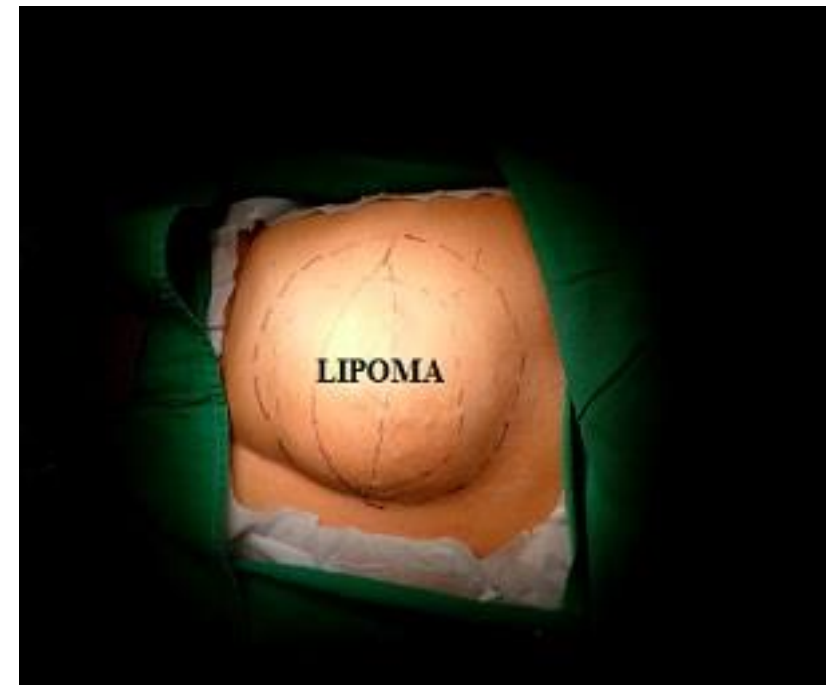

Figure 1: Giant lipoma seen in the lower part of the left posterior thoracic region with patient in right lateral position.

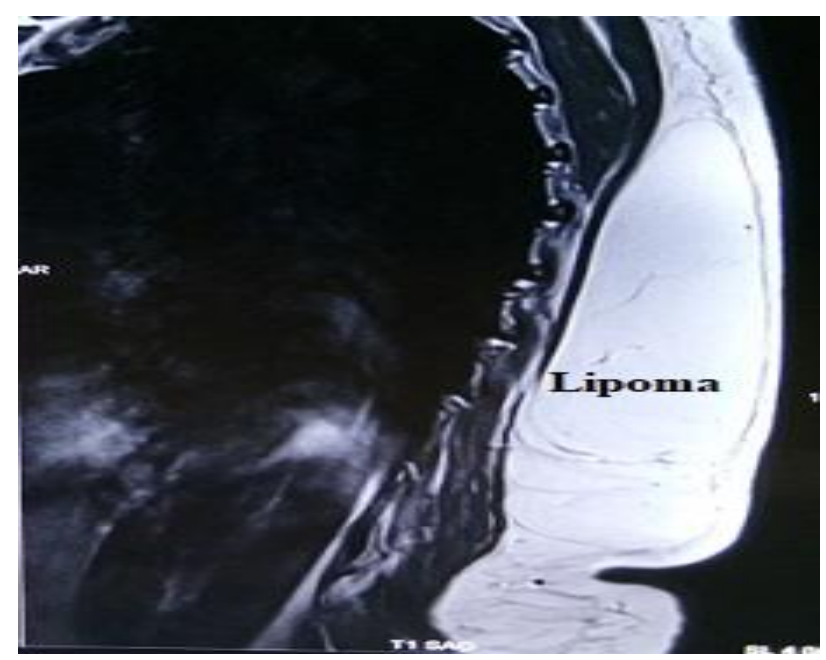

Figure 2: MRI (sagittal plane) showing lipoma.

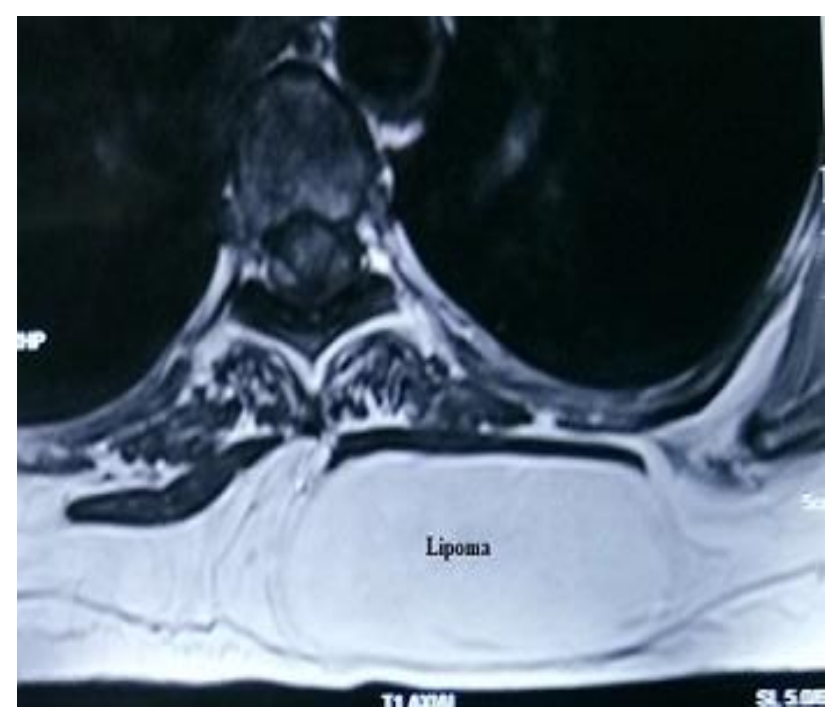

Figure 3: MRI (transverse plane) showing the lipoma.

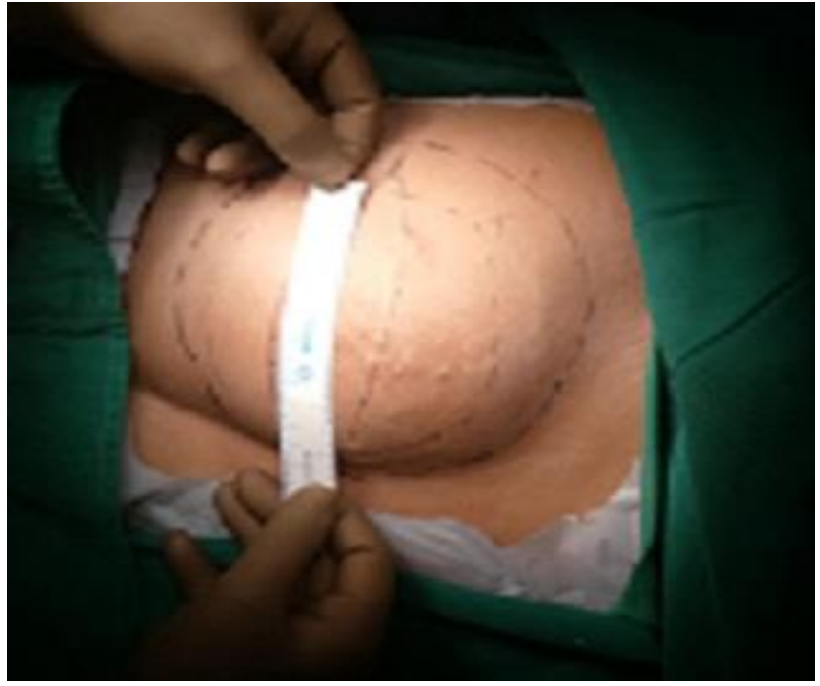

Figure 4: Extent of the tumor and incision marked.

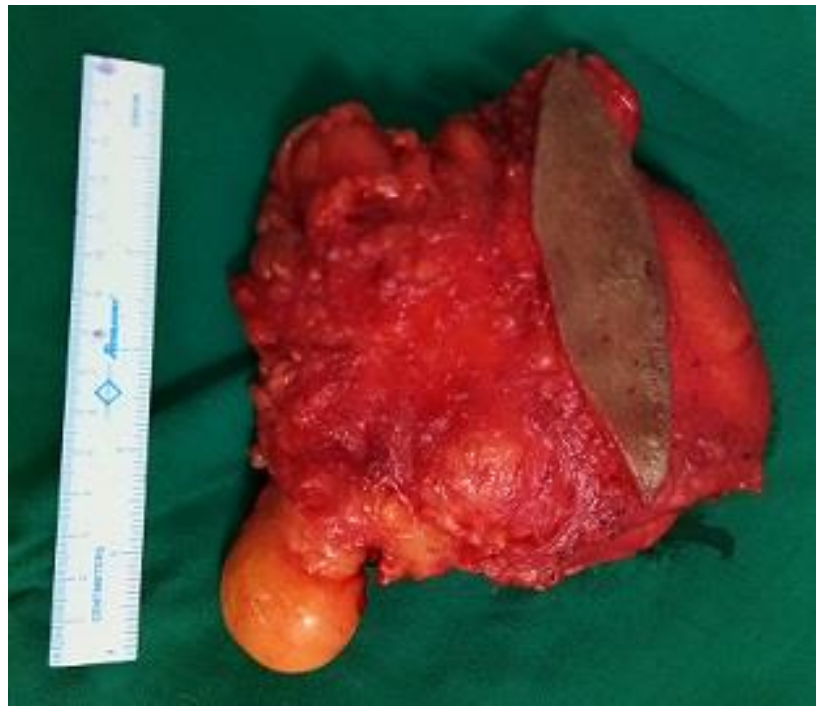

Figure 5: Excised specimen measuring diameter greater than $10 \mathrm{~cm}$.

\section{DISCUSSION}

A giant lipoma is defined as one, whose size exceeds 10 $\mathrm{cm}$ in diameter or weighs more than 1000 grams. ${ }^{2}$ Giant lipomas have predilection for the back and the posterior cervical region. The exact etiology of giant lipomas continues to be an enigma. Many hypotheses have been put forth which suggest an association with raised cholesterol, severe obesity, and trauma., ${ }^{3,4}$ The role of trauma in the etiology of lipoma is based on various assumptions. One theory suggests that blunt trauma causes rupture of the fibrous septa and connections between the fascia and the skin, thereby allowing fat herniation through the tissue planes, giving rise to a pseudo lipoma. Trauma also induces cytokine release which triggers free adipose differentiation as well as maturation. 5,6 Association with gene rearrangement of chromosome 12 has been found in patients with solitary 
lipoma as well as abnormalities in the HMGA2-LPP fusion genes. ${ }^{1}$

Majority of lipomas present as slow growing soft tissue tumors. They assume large size in certain regions such as back, shoulder, and neck. Soft consistency and lobulation are diagnostic of lipomas. Sudden rapid growth over a short period of time accompanied with pain, especially in deep seated lipomas is suggestive of sarcomatous change. This is typically seen in retroperitoneal lipomas.

Imaging is an essential component of diagnostics. Ultrasound usually shows a well circumscribed, encapsulated mass. Even though there may be variations in the echogenicity, most of the lipomas are either iso or hyper echoic when compared to muscle. CT scan reveals an encapsulated low-density homogeneous mask. MRI is the most frequently used radiological modality, by virtue of the fact that it has extremely high soft tissue resolution. This enables detailed evaluation of the distribution and depth of the mass as was seen in the MRI of the case presented (Figure 2 and 3). Lipomas do not exhibit any contrast enhancement both on MRI as well as CT scan. ${ }^{1,7}$

An FNAC can be done to ascertain the diagnosis, especially when there is a strong suspicion of a liposarcoma as revealed by clinical features on imaging. ${ }^{7}$ In the case presented FNAC was not done as there was no suspicion of a sarcomatous change based on clinical and MRI findings.

Wide and complete local excision of the entire tumor is the main stay of treatment. ${ }^{7,8}$ If there is a suspicion of the liposarcoma, a frozen section can be done intraoperatively followed by wide excision based on oncological principles. However, the incidence of such a situation is extremely less. In all giant lipomas, it is a good practice to mark the extent of tumors before planning the incision as was done in the case presented (Figure 4). This ensures ease at complete excision of the tumor. It also aids in achieving a better cosmetic outcome. Utmost care should be taken to ensure that the entire encapsulated mass is excised in order to prevent recurrence. Since the dead space created by excision of tumor is large, a closed negative suction drain should be placed in this space and brought out through a separate incision. This aids in obliteration of dead space, prevention of seromas, and better cosmetic outcomes.

For histopathological evaluation of the tumor excised, it is essential to rule out the presence of liposarcoma in a patient with completely excised tumor though the incidence is very less.
Other modalities of treatment described for lipomas such as liposuction are of no practical utility in case of giant lipomas.

\section{CONCLUSION}

Giant lipomas necessitate critical clinical evaluation. MRI is the investigation of choice for determining infiltration of surrounding tissues. FNAC or preferably a frozen section intraoperatively is advisable in suspected sarcomatous change in a giant lipoma. Complete surgical excision is the treatment of choice for all giant lipomas.

\section{ACKNOWLEDGEMENTS}

The authors would like to thank dean, D. Y. Patil university school of medicine, Navi Mumbai, India, for permission to publish the case report.

Funding: No funding sources

Conflict of interest: None declared

Ethical approval: Not required

\section{REFERENCES}

1. Grimaldi L, Cuomo R, Castagna A, Sisti A, Nisi G, Brandi $\mathrm{C}$ et al. Giant lipoma of the back. Indian $\mathbf{J}$ Plast Surg. 2015;48(2):220-1.

2. Sanchez MR, Golomb FM, Moy JA, Potozkin JR. Giant lipoma: case report and review of the literature. J Am Acad Dermatol. 1993;28(2 Pt 1):266-8.

3. Rubinstein A, Goor Y, Gazit E, Cabili S. Nonsymmetric subcutaneous lipomatosis associated with familial combined hyperlipidaemia. Br J Dermatol. 1989;120(5):689-94.

4. Zografos GC, Kouerinis I, Kalliopi P, Karmen K, Evagelos M, Androulakis G. Giant lipoma of the thigh in a patient with morbid obesity. Plast Reconstr Surg. 2002;109(4):1467-8

5. Aust MC, Spies M, Kall S, Jokuszies A, Gohritz A, Vogt P. Posttraumatic lipoma: fact or fiction? Skinmed. 2007;6(6):266-70.

6. Signorini M, Campiglio GL. Posttraumatic lipomas: where do they really come from? Plast Reconstr Surg. 1998;103:699.

7. Silistreli OK, Durmuş EU, Ulusal BG, Oztan Y, Görgü M. What should be the treatment modality in giant cutaneous lipomas? Review of the literature and report of 4 cases. $\mathrm{Br} \mathrm{J}$ Plast Surg. 2005;58(3):394-8.

8. Yakubu AA, Edino ST, Mohammed AZ, Sheshe AA, Alhassan SU. Giant and complicated subcutaneous lipoma of the neck. West Afr J Med. 2008;27(1):446.

Cite this article as: Vagholkar K, Bhatnagar I, Vagholkar S. Giant lipoma over the back. Int Surg J 2022;9:687-9. 